\title{
Hybrid Geopolymeric Foams for the Removal of Metallic Ions from Aqueous Waste Solutions
}

\author{
Giuseppina Roviello ${ }^{1,2, *}$, Elena Chianese ${ }^{3, *}$, Claudio Ferone ${ }^{1,2} \mathbb{0}$, Laura Ricciotti ${ }^{1}$, \\ Valentina Roviello ${ }^{4}$, Raffaele Cioffi ${ }^{1,2}$ and Oreste Tarallo ${ }^{5}$ (D) \\ 1 Dipartimento di Ingegneria, Università di Napoli 'Parthenope', Centro Direzionale, Isola C4, 80143 Napoli, \\ Italy; claudio.ferone@uniparthenope.it (C.F.); laura.ricciotti@uniparthenope.it (L.R.); \\ raffaele.cioffi@uniparthenope.it (R.C.) \\ 2 INSTM Research Group Napoli Parthenope, National Consortium for Science and Technology of Materials, \\ Via G. Giusti, 950121 Firenze, Italy \\ 3 Dipartimento di Scienze e Tecnologie, Università di Napoli ‘Parthenope’, Centro Direzionale, Isola C4, \\ 80143 Napoli, Italy \\ 4 Dipartimento di Ingegneria Chimica, dei Materiali e della Produzione Industriale, Università di Napoli \\ Federico II, Piazzale V. Tecchio 80, 80125 Naples, Italy; valentina.roviello@unina.it \\ 5 Dipartimento di Scienze Chimiche, Università degli Studi di Napoli “Federico II", Complesso Universitario \\ di Monte S. Angelo, via Cintia, 80126 Napoli, Italy; oreste.tarallo@unina.it \\ * Correspondence: giuseppina.roviello@uniparthenope.it (G.R.); elena.chianese@uniparthenope.it (E.C.)
}

Received: 22 October 2019; Accepted: 4 December 2019; Published: 7 December 2019

check for updates

\begin{abstract}
For the first time, hybrid organic-inorganic geopolymeric foams were successfully used as monolithic adsorbents for the removal of metallic ions pollutants from wastewaters. The foams were realized by the in situ foaming of a hybrid geopolymer obtained by a reaction of metakaolin and polysiloxane oligomers under strong alkaline conditions and then cured at room temperature. In this way, porous materials with densities ranging from 0.4 to $0.7 \mathrm{~g} / \mathrm{cm}^{3}$ and showing good mechanical properties were produced. With the aim of producing self-standing monolithic adsorbents for the removal of metallic ions pollutants from wastewaters, these porous hybrid geopolymers were subjected to a washing pretreatment with ultrapure water, dried, and then used for absorption tests by dipping them into an aqueous solution with an initial concentration of $20 \mathrm{ppm}$ of $\mathrm{Pb}^{2+}, \mathrm{Cd}^{2+}, \mathrm{Cu}^{2+}$, and $\mathrm{Zn}^{2+}$ ions. Preliminary results indicated that all the tested materials are effective in the adsorption of the tested metal ions and do not release the removed metal ions upon sinking in ultrapure water, even for a very long time. Interestingly, compressive strength tests performed before and after the washing treatments show that the foamed samples remain intact and maintain their physical-mechanical characteristics, suggesting that these kinds of materials are promising candidates for the production of self-standing, monolithic adsorbent substrates that can be easily collected when exhausted, which is a major advantage in comparison with the use of powdered adsorbents. Moreover, since these materials can be obtained by a simple and versatile experimental procedure, they could be easily shaped or directly foamed into precast molds to be used in packed beds as membranes.
\end{abstract}

Keywords: porous materials; hybrids; geopolymer; adsorption; heavy metals

\section{Introduction}

Aqueous wastes deriving from different kind of anthropic activities, such as mining or metal industries, contain high concentrations of cations of heavy metals such as $\mathrm{Cd}, \mathrm{Pb}, \mathrm{Cu}, \mathrm{Cr}, \mathrm{Zi}$, and $\mathrm{Ni}$. These wastes represent a serious threat to the contamination of soils and waters [1-3], as they accumulate in living organisms, generating serious and often lethal pathologies. Therefore, the removal of heavy metal cations from the wastewater of industrial or agricultural activities, before they are released 
into the environment, is an urgent necessity that has been the subject of studies for several years now. Many effective methods for metals removal from wastewater were developed up to now, including ion exchange, chemical precipitation, electrochemical treatment, reverse osmosis, adsorption, and biosorption [4,5]. In recent years, adsorption has become the central research focus due to its easy approach, effectiveness, and low cost.

Inorganic porous materials are widely studied in the developing of membranes or high-efficiency adsorption materials [6]. In this field, great attention has been devoted to zeolites for their effectiveness in the removal of heavy metal cations from wastewater [7]. Ion exchange properties shown by these materials are due to their unique crystalline microporous structure, characterized by fixed pore dimensions that make them selectively accessible to metal cations, depending on their charge and size $[8,9]$.

Geopolymers are inorganic materials, similar to zeolites, but showing an amorphous three-dimensional aluminosilicate network structure. Unlike zeolites, these materials are characterized by simple and cost-effective synthesis procedures [10] based on the reaction of natural Si- and Al-rich materials, such as metakaolin or industrial by-products (fly ash, blast furnace slag, muds) in highly alkaline aqueous solutions. A polycondensation reaction leads to the formation of a gel network consisting of $\mathrm{SiO}_{4}$ and $\mathrm{AlO}_{4}$ tetrahedra sharing oxygen corners and forming rings of various sizes, which are analogous to those found in zeolites.

Geopolymers exhibit a wide variety of technologically relevant properties, such as high compressive strength [11], fire resistance, and low shrinkage [12]. For these reasons, geopolymers seem to be a valuable alternative to ordinary Portland cement, which is also thanks to their environmentally sustainable fingerprint [13-15] being mainly associated with the reduced $\mathrm{CO}_{2}$ emissions characterizing the raw materials from which they can be obtained [16]. When foaming agents (as hydrogen peroxide or metallic $\mathrm{Al}$ or Si powders) are added into the geopolymer paste during its consolidation, porous materials with pore sizes ranging from a few tenths of nanometers to a few millimeters can be obtained [17-19]. At variance with conventional techniques used for the production of porous ceramics [20], no high-temperature treatments (such as burn out of organics and sintering) are necessary for this process.

Many studies report on the capability of geopolymers to remove heavy metal ions from aqueous solutions [21-29]. These studies are all related to metakaolin or fly ash-based geopolymers. However, when immersed in water, in some cases, the formation of efflorescence has been found, while for samples characterized by elevated $\mathrm{Na}_{2} \mathrm{O} / \mathrm{Al}_{2} \mathrm{O}_{3}$ ratios $(>1.5)$, the disintegration of the specimen has been experienced [30]. Moreover, in order to maximize the surface area of the adsorbent, these materials are not used as large monolithic artifacts; instead, they usually are finely ground and reduced to a fine powder which is then further sieved [31].

Recently, we succeeded in synthetizing geopolymer-based organic-inorganic composites and hybrid materials by reacting an aluminosilicate source and an aqueous alkali hydroxide and/or alkalisilicate solution with mixtures of dialkylsiloxane oligomers or organic resins precursors [32,33]. With respect to the unmodified geopolymers with an analogous Si/Al ratio, these materials are characterized by enhanced mechanical properties, along with good temperature and fire resistance [34-40]. By adding a foaming agent, these materials have been obtained as foams with densities ranging between 0.2 and $0.8 \mathrm{~g} / \mathrm{cm}^{3}$ and showing good mechanical properties and low thermal conductivity, which makes them particularly suitable for the utilization as insulating materials in the field of constructions [39-41].

To date, to the best of our knowledge, no studies have been reported on the absorption capability of geopolymer-based organic-inorganic hybrid foams. This last class of materials could be of particular interest since, due to its superior mechanical resistance with respect to unmodified geopolymers with analogous chemical composition [33], it could be effectively used as adsorbent for the production of self-standing large monolithic absorbent substrates, with no need to be previously ground. In fact, they could combine the well-known adsorbent capacity of geopolymers with the improved mechanical performance characterizing geopolymeric hybrid foams [39], which would make them more suitable for 
practical applications in aqueous environments than the unmodified geopolymers. As a matter of fact, geopolymeric hybrid foams combine (i) a tunable porosity and morphology with versatile rheological properties that make them easy to mold; (ii) good mechanical properties after the consolidation, which makes them useful for the production of reusable large filters or membranes that are capable of being recovered intact after use; and (iii) a simple, environmentally friendly, and cheap process of production [33,39].

In this paper, for the first time, the capability of these hybrid organic-inorganic geopolymeric foams to act as sieves for removing heavy metal cations from aqueous solutions in the form of self-standing large substrates has been studied. The collected results indicate that these hybrid materials are effective in the adsorption of several metallic species, such as $\mathrm{Zn}^{2+}, \mathrm{Cd}^{2+}, \mathrm{Pb}^{2+}$, and $\mathrm{Cu}^{2+}$ ions, which can be acutely toxic for humans and other organisms at elevated concentrations, whilst a prolonged exposure to lower concentrations can cause serious diseases [42-44]. Moreover, these new foams do not release the removed metal ions when placed again in ultrapure water, even for a very long time. Finally, compressive strength tests performed before and after the washing treatments show that the foamed samples remain intact and maintain their physical-mechanical characteristics, suggesting that they could be effectively used as an adsorbent for the production of self-standing large absorbent substrates, which could be easily shaped or directly foamed into precast molds.

\section{Materials and Method}

\subsection{Materials}

The metakaolin that was used in this paper as a raw material was provided by Neuchem S.r.l. (Milan, Italy), while sodium silicate solution was supplied by Prochin Italia S.r.l (Caserta, Italy). Table 1 reports their chemical composition. Reagent grade sodium hydroxide and silicon powder ( 325 mesh) were supplied by Sigma-Aldrich (St. Louis, MO, USA). A commercial oligomeric dimethylsiloxane mixture, Globasil AL20, was purchased from Globalchimica S.r.l (Turin, Italy).

Table 1. Chemical composition (weight \%) in terms of major oxides of the metakaolin and the sodium silicate solution used to obtain the specimens tested in this paper.

\begin{tabular}{cccccccc}
\hline \multicolumn{7}{c}{ Metakaolin } \\
\hline $\mathrm{SiO}_{2}$ & $\mathrm{Al}_{2} \mathrm{O}_{3}$ & $\mathrm{TiO}_{2}$ & $\mathrm{Fe}_{2} \mathrm{O}_{3}$ & $\mathrm{~K}_{2} \mathrm{O}$ & $\mathrm{MgO}$ & $\mathrm{CaO}$ & others \\
\hline 52.90 & 41.90 & 1.80 & 1.60 & 0.77 & 0.19 & 0.17 & 0.67 \\
\hline \multicolumn{7}{c}{ Sodium Silicate Solution } \\
\hline $\mathrm{SiO}_{2}$ & $\mathrm{Na}_{2} \mathrm{O}$ & $\mathrm{H}_{2} \mathrm{O}$ & & & \\
\hline 27.40 & 8.15 & 64.45 & & \\
\hline
\end{tabular}

Single component standard solutions of lead, copper, zinc and cadmium cations (in concentration of $1000 \mathrm{ppb}$ ) and multistandard solutions of anions and cations were obtained from Honeywell Fluka ${ }^{\mathrm{TM}}$ (Bucharest, Romania).

\subsection{Preparation of Hybrid Geopolymer Foams (GSil)}

Hybrid polysiloxane-geopolymer slurries were prepared as described elsewhere [33,39]. In order to obtain a set of samples characterized by a different degree of porosity, silicon powder was added to two distinct aliquots of the hybrid suspensions in $0.03 \mathrm{wt} \%$ and $0.12 \mathrm{wt} \%$ ratios, and then the whole system was mixed for a further $5 \mathrm{~min}$ at $1000 \mathrm{rpm}$. The obtained foamed samples, once consolidated after curing treatments (see below), are hereafter indicated as GSil03 and GSil12, respectively. The relevant details of the mix design are reported in Table 2. 
Table 2. Mix composition ( $\mathrm{w} t \%)$, apparent density, and mass of the studied samples. MK = metakaolin; $\mathrm{SS}=$ sodium silicate solution; DMS = oligomeric dimethylsiloxane mixture; $\mathrm{Si}=$ silicon powder.

\begin{tabular}{cccccccc}
\hline Sample & MK & SS & NaOH & DMS & Si & $\begin{array}{c}\text { Apparent } \\
\text { Density }\left(\mathbf{g ~ c m}^{-3}\right)\end{array}$ & Sample's Mass * (g) \\
\hline GSil03 & 37.4 & 45.0 & 7.6 & 10.0 & 0.03 & $0.701 \pm 0.002$ & $\begin{array}{l}2.60990 \pm 0.00001(\mathrm{~A}) \\
8.33520 \pm 0.00001(\mathrm{~B})\end{array}$ \\
\hline GSil12 & 37.4 & 45.0 & 7.6 & 10.0 & 0.12 & $0.396 \pm 0.003$ & $\begin{array}{l}2.93095 \pm 0.00001(\mathrm{~A}) \\
9.02261 \pm 0.00001(\mathrm{~B})\end{array}$ \\
\hline \multicolumn{7}{c}{ * Mass of the samples used for the adsorption tests after washing treatment and drying. }
\end{tabular}

As soon as prepared, all the foaming slurries were casted into cubic molds and cured in $>95 \%$ relative humidity conditions at $\approx 22^{\circ} \mathrm{C}$ for one day and then at $60{ }^{\circ} \mathrm{C}$ for further $24 \mathrm{~h}$. Afterwards, the samples were kept at the same temperature in $>95 \%$ relative humidity conditions for a further 5 days and finally for a further 21 days in air.

In order to perform microstructural and mechanical studies and evaluate the adsorption capability with respect to different metal ions, for each composition, samples of different dimensions and shapes were prepared. In particular, adsorption tests were performed on platelets obtained by cutting each sample into $2 \times 20 \times 20 \mathrm{~mm}^{3}$ and $5 \times 20 \times 20 \mathrm{~mm}^{3}$ slices: the samples with a thickness equal to $2 \mathrm{~mm}$ were named samples " $\mathrm{A}$ " (GSil03A, GSil12A), while those $5 \mathrm{~mm}$ thick were named samples " $\mathrm{B}$ " (GSil03B, GSil12B). The dimensions of the specimens were chosen in order to fit the in-house developed specimen holders used for adsorption and desorption tests. The apparent density and mass of the samples used for the adsorption tests are reported in Table 2. Before performing the adsorption tests, the obtained foamed platelets were subjected to a preconditioning washing step, as will be described in the following sections.

\subsection{Methods}

\subsubsection{Physical and Microstructural Assessment}

SEM analyses were carried out by means of a Nova NanoSem 450 FEI Microscope. Microcomputed tomography $(\mu \mathrm{CT})$ was performed at the ATeN Center (University of Palermo, Italy) with a $\mu \mathrm{CT}$ scanner (Skyscan 1272, Bruker, Kontich, Belgium) equipped with a $1 \mathrm{~mm}$ aluminum filter. The samples were scanned at $40 \mathrm{kV}$ source voltage and $250 \mathrm{~mA}$ current. A rotation of $180^{\circ}$ by $0.2^{\circ}$ steps was carried out. Pixel size was $7.4 \mu \mathrm{m}$. Two-dimensional (2D) reconstructions were carried out using the NRecon software (version 1.6.10.2, Allentown, PA, USA) with 8-bit color depth and 265 gray level. After that, the whole set of raw images were displayed in 3D by CTVox software. Quantitative analyses were carried out via CTan software (version 1.16.1.0). These measurements allowed also evaluating the porosity of the samples.

Apparent density evaluations were carried out by means of an OHAUS-PA213 hydrostatic balance provided by Pioneer.

\subsubsection{Compressive Behavior}

Uniaxial compressive tests were carried out as already reported in ref. [39] on $50 \times 50 \times 50 \mathrm{~mm}^{3}$ cubic specimens. Two sets of samples were examined: the first set of measurements were performed on "as-prepared" specimens, i.e., on samples as obtained after the curing stage, before the washing treatments; the second set of measurements was performed on the specimens after having carried out the washing procedure described in Section 2.3.3 on them and until the ion release measurements and the $\mathrm{pH}$ of the washing solutions were the same as those recorded for the specimens subjected to the adsorption tests described in Section 3.2. For each sample type, at least three specimens were tested under displacement control in order to obtain the corresponding stress-strain curve, compressive strength, and Young's modulus, and the values reported are the averages of the values obtained. More experimental details are reported in ref. [39]. 


\subsubsection{Washing Procedure and Adsorption/Desorption Tests}

Hybrid geopolymer foams were carefully washed to clean their surface and internal pores from residues due to the synthesis process and cutting step. The washing procedure was also necessary to avoid contamination of the aqueous solution during metals adsorption tests and to control the effects of the artifacts on the alkalinity of the aqueous solution. In fact, it was observed that a metakaolin-based geopolymer can determine an increase of the $\mathrm{pH}$ of aqueous solution, thus conditioning metal's precipitation equilibrium [27].

To this aim, each sample was dipped in $50 \mathrm{~mL}$ of ultrapure water for 7 days. Periodically, the bath was manually shaken. After this time, aqueous solutions were recovered, filtered with filters with pores of $0.2 \mu \mathrm{m}$, and frozen until analyses were performed on them. The process was repeated four times, and chemical analyses were carried out on each washing solution obtained (see the next paragraph). After washing steps, samples were dried in an oven at $50{ }^{\circ} \mathrm{C}$ for $24 \mathrm{~h}$ until constant mass and then tested for their adsorption capacity.

Adsorption tests were performed on each hybrid foam by dipping the platelets in a bath containing $50 \mathrm{~mL}$ of an aqueous solution of each metal cation $\left(\mathrm{Pb}^{2+}, \mathrm{Cd}^{2+}, \mathrm{Cu}^{2+}, \mathrm{Zn}^{2+}\right)$ with an initial concentration of $20 \mathrm{ppm}$. These solutions were obtained by diluting single metal standard solutions at a starting concentration of $1000 \mathrm{ppm}$.

Each foam was kept in contact with the solution for 7 days; after this time, solutions were recovered, filtered with filters with pores of $0.2 \mu \mathrm{m}$, and then frozen until analyzed.

Metal cations desorption tests were performed as follows. Each hybrid foam used for absorption tests was kept for 7 days in a bath with $50 \mathrm{~mL}$ of ultrapure water at room temperature $\left(24^{\circ} \mathrm{C}\right)$ without agitation. After this contact time, solution baths were recovered and analyzed for their metal cations content.

\subsubsection{Chemical Analyses of Aqueous Solutions from Washing Steps: Absorption and Desorption Tests}

Aqueous solutions from washing steps were analyzed for their content of major ions and some metal cations $\left(\mathrm{Pb}^{2+}, \mathrm{Cd}^{2+}, \mathrm{Cu}^{2+}, \mathrm{Zn}^{2+}\right)$, while solutions from absorption and desorption tests were analyzed for their metal cations content only.

For the major ions, determination ionic chromatography was performed with a Dionex 1100 system, which was designed for the contemporary determinations of anions and cations; specifically, anions $\left(\mathrm{Cl}^{-}, \mathrm{F}^{-}, \mathrm{Br}^{-}, \mathrm{NO}_{2}{ }^{-}, \mathrm{NO}_{3}{ }^{-}, \mathrm{PO}_{4}{ }^{3-}\right.$, and $\mathrm{SO}_{4}{ }^{2-}$ as inorganic species, and $\mathrm{HCOO}^{-}, \mathrm{CH}_{3} \mathrm{COO}^{-}$, and $\mathrm{C}_{2} \mathrm{O}_{4}{ }^{-2}$ as organic species) were determined using a line constituted by an ASRS 300-4 mm suppressor with an applied current of $33 \mathrm{~mA}$, an AS22 column working with a cell volume of $100 \mu \mathrm{L}$, and a buffer solution with title of $3.5 \mathrm{mM}$ of sodium carbonate/bicarbonate as eluent (flow rate $1.20 \mathrm{~mL} / \mathrm{min})$. The line for cations $\left(\mathrm{Li}^{+}, \mathrm{Na}^{+}, \mathrm{K}^{+}, \mathrm{NH}_{4}{ }^{+}, \mathrm{Ca}^{2+}\right.$, and $\left.\mathrm{Mg}^{2+}\right)$ determination was constituted by a CERS 500-4 mm suppressor with an applied current of $15 \mathrm{~mA}$, a CS12A column working with a cell volume of $25 \mu \mathrm{L}$, and $20 \mathrm{mM}$ methanesulfonic acid solution as the eluent (flow rate $0.25 \mathrm{~mL} / \mathrm{min}$ ); for both anions and cations, calibration curves were defined using certified multistandard solutions.

The voltammetric analyses for metals determination were carried out with a Metrohm 797 VA Computrace equipped with a multimode working $\mathrm{Hg}$ electrode. $\mathrm{An} \mathrm{Ag} / \mathrm{AgCl}$ electrode was used as the reference, and a Pt electrode as the auxiliary electrode. The standard addition method was applied as the calibration method to limit the matrix effects. All elements were quantified using linear regression based on the height of the peaks of the voltammograms. This method allows the determination of zinc, cadmium, lead, and copper. The $\mathrm{pH}$ of the solutions was determined with a Metrohm $781 \mathrm{pH} / \mathrm{Ion}$ meter. The compliance and reliability of analytical procedures were discussed in ref. [45].

The percentage removal efficiency $(E)$ and efficiency for mass unit of geopolymer $(Q)$ were evaluated as follows:

$$
\begin{gathered}
E(\%)=\frac{C_{o}-C_{e}}{C_{o}} \times 100 \\
Q=\frac{\left(C_{o}-C_{e}\right) V}{W}
\end{gathered}
$$


where $C_{o}$ was the initial metal concentration (as $\mathrm{mg} / \mathrm{L}$ ), $C_{e}$ was the final metal concentration after the adsorption test (as $\mathrm{mg} / \mathrm{L}$ ), $V$ was the volume of solution (as $\mathrm{L}$ ), and $W$ was sample weight (as $\mathrm{g}$ ).

\section{Result and Discussion}

\subsection{Porous Hybrid Geopolymeric Materials: Preparation and Microstructural Characterization}

As stated before, in this paper, hybrid organic-inorganic geopolymeric foams were successfully used as monolithic adsorbents for the removal of metallic ions pollutants from wastewaters. To this aim, two sets of foamed hybrid samples with different porosity, GSil03 and GSil12, were prepared. In particular, in order to evaluate the adsorption capability of these materials as monolithic adsorbents, rectangular specimens of different dimensions and thicknesses (Table 2) were shaped. The advantage in the obtainment and use of hybrid geopolymer-based materials with respect to unmodified geopolymers relies in the fact that the homogeneous combination of inorganic and organic moieties in a single-phase material provides unique possibilities to obtain properties that are not found in the organic polymer or in the inorganic materials independently. In particular, the produced hybrid foams show significantly increased mechanical properties [33] with respect to the unmodified geopolymer reported in the literature [46-50].

The hybrid foams were prepared by applying a synthetic approach earlier developed by some of us [33] consisting of the simultaneous polymerization of a commercial oligomeric polydimethylsiloxane mixture with metakaolin (MK) under strong alkaline conditions. During the polycondensation reaction, the formation of chemical bonds between the reactive MK-based geopolymeric suspension and the polydimethylsiloxane mixtures takes place, thus allowing the obtainment of a hybrid material [33]. It is worth emphasizing that the choice of metakaolin as the aluminosilicate source has been driven by the consideration that this material is purer and more homogeneous in its chemical composition than the industrial by-products [51] that are commonly used as raw materials. For this reason, metakaolin is more suitable than ash or muds for the obtainment of high value-added artifacts, such as those proposed in the present paper.

In order to obtain monolithic foams characterized by different porosity, $\mathrm{Si}^{0}$ powder was added as the blowing agent into the freshly prepared slurry: the formation of voids takes place due to the evolution of hydrogen gas during the reaction of silicon with water molecules in alkaline environment. Obviously, the foaming process was strongly dependent on the amount of $\mathrm{Si}^{0}$ added, and as expected, the volume expansion of the slurry increased by increasing the amount of the foaming agent; on the contrary, the density of the cured porous materials decreases as the amount of foaming agent increases (Table 2).

The morphology of the foamed specimens obtained has been studied in detail by means of X-ray microtomography and SEM. Figure 1 shows 2D and 3D X-ray microtomography images of $\left(1 \times 1 \times 1 \mathrm{~cm}^{3}\right)$ slices of GSil03 and GSil12 samples. These images show the presence of pores of different size and shape that, in both cases, are homogenously distributed within the sample. It is worth noting that the highest $\mathrm{Si}^{0}$ addition as the foaming agent performed in GSil12 (Figure 1C,D) produces a foam of lower density: in particular, by processing 2D and 3D microtomography, it resulted that the total porosity of the samples GSil03 was $\approx 50 \%$, while that of GSil12 foam was $\approx 72 \%$. This porosity turned out to be constituted almost exclusively by open porosity $(\approx 46 \%$ for GSil03 and $\approx 71.7 \%$ for GSil12). As far as the shape of the pores, GSil03 presented almost perfectly circular pores, with a minor anisotropy along the main foaming direction (Figure 1A,B). Instead, the GSil12 sample is characterized by a less regular shape of pores, which is probably due to coalescence phenomena (Figure 1C,D). Moreover, as shown by the pore distribution analysis reported in Figure 2a, $90 \%$ of the pores of the GSil03 sample had a size between a few microns up to $100 \mu \mathrm{m}, \sim 6 \%$ of the pores had a size included in the range $100-200 \mu \mathrm{m}$, and only $\sim 4 \%$ of the pores were over $200 \mu \mathrm{m}$. Instead, in the case of GSil12 (Figure $2 \mathrm{~b}$ ), the percentage of pore diameters up to $100 \mu \mathrm{m}$ is only $\sim 31 \%$, while most of the pores $(\sim 58 \%)$ have a diameter in the range $200-400 \mu \mathrm{m}$. Meanwhile, $11 \%$ of pores in this sample present a diameter larger 
than $400 \mu \mathrm{m}$. Of course, this very different pore distribution in the two foams and the fact that GSil12 foam presents the majority of pores larger than $100 \mu \mathrm{m}$ is due to the coalescence of the gas bubbles due to the use of the highest quantity of foaming agent.
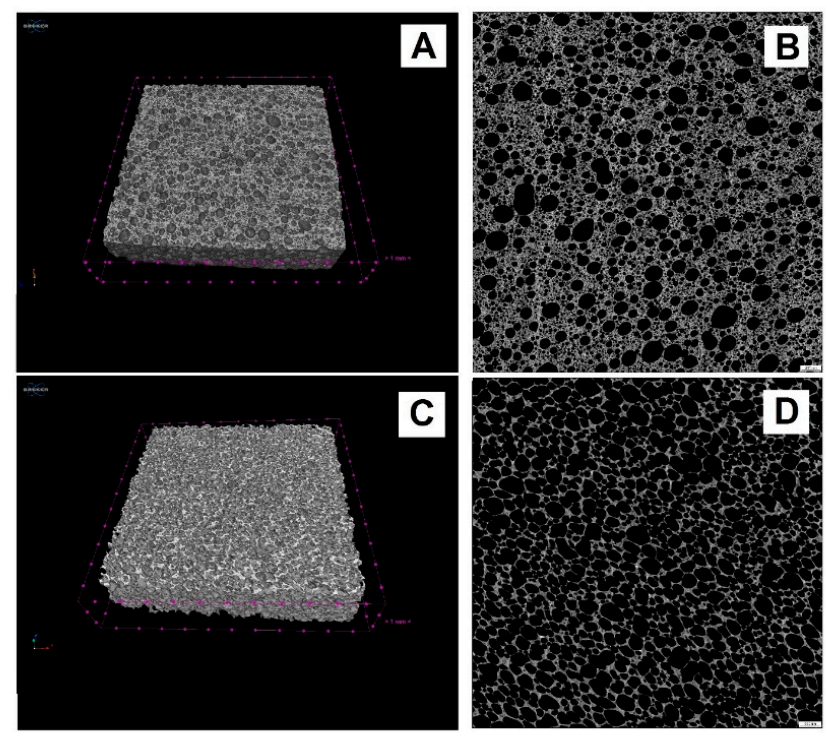

Figure 1. X-ray microtomography images of 3D slice (on the left) and $2 \mathrm{D}$ slice (on the right) of the GSil03 sample (A,B) and of the GSil12 sample (C,D). The scale bar is $500 \mu \mathrm{m}$.
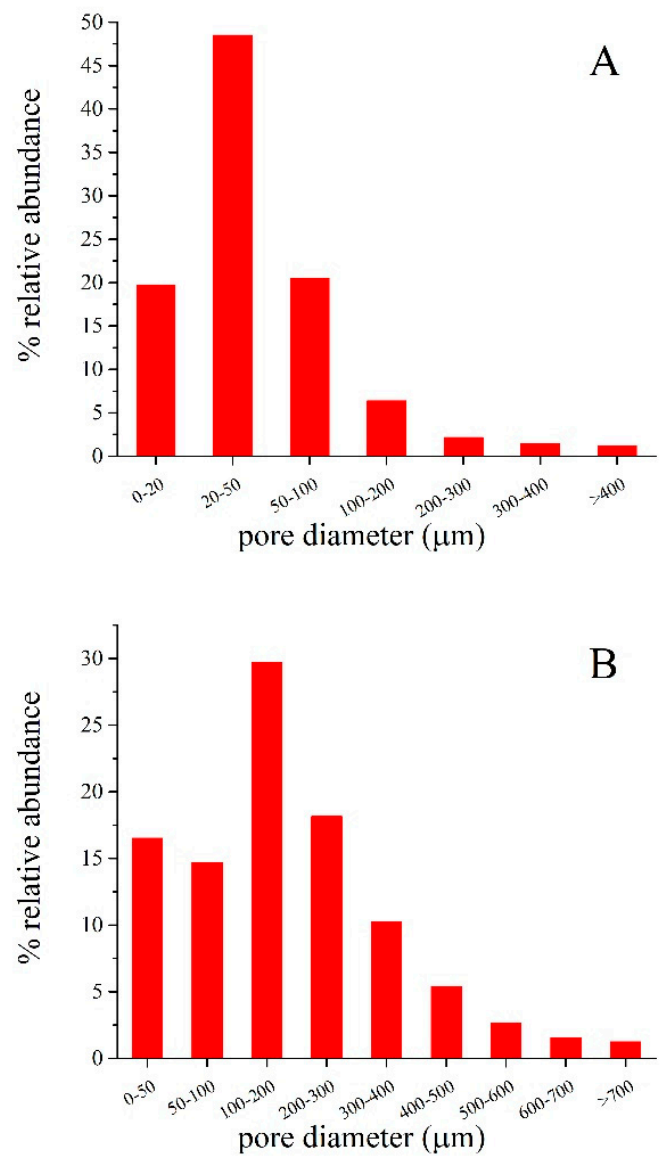

Figure 2. Pore size distribution in GSil03 (A) and GSil12 (B) as obtained by analysis of the microtomographies reported in Figure 1. 
In order to get a better insight of the microstructure of the samples prepared, SEM micrographs of freshly obtained fractured surfaces of the studied foams were performed. Figure 3 shows SEM images of the GSil03 sample after the washing pretreatments, as it was used for the adsorption tests (see Section 3.3). The results of the SEM investigations support the findings of the microtomography, but they also additionally provide insight into the structure of the walls between the pores and of the pore surface itself. In particular, this sample shows a quite regular distribution of the pores due to the evolution of hydrogen gas during the foaming process (see Figure 3a,b). A deeper inspection of pore walls (Figure $3 \mathrm{c}$ ) points out that the sample exhibits a continuous and uniform structure in which no segregation phenomena are observable, even at the nanometric scale level, although it contains an organic component. This is attributable to the formation of a tridimensional and interpenetrated network in which the inorganic (geopolymeric) phase and the polysiloxane component are able to strongly interact by means of the formation of chemical bonds between the aluminosilicate and organo-siloxane units. Within pores, the presence of a nodular morphology reminiscent of the gel formation in the early stages of geopolymeritazion, with an average diameter of nodules of about 40-50 nm, is also evident (Figure 3d) [33].
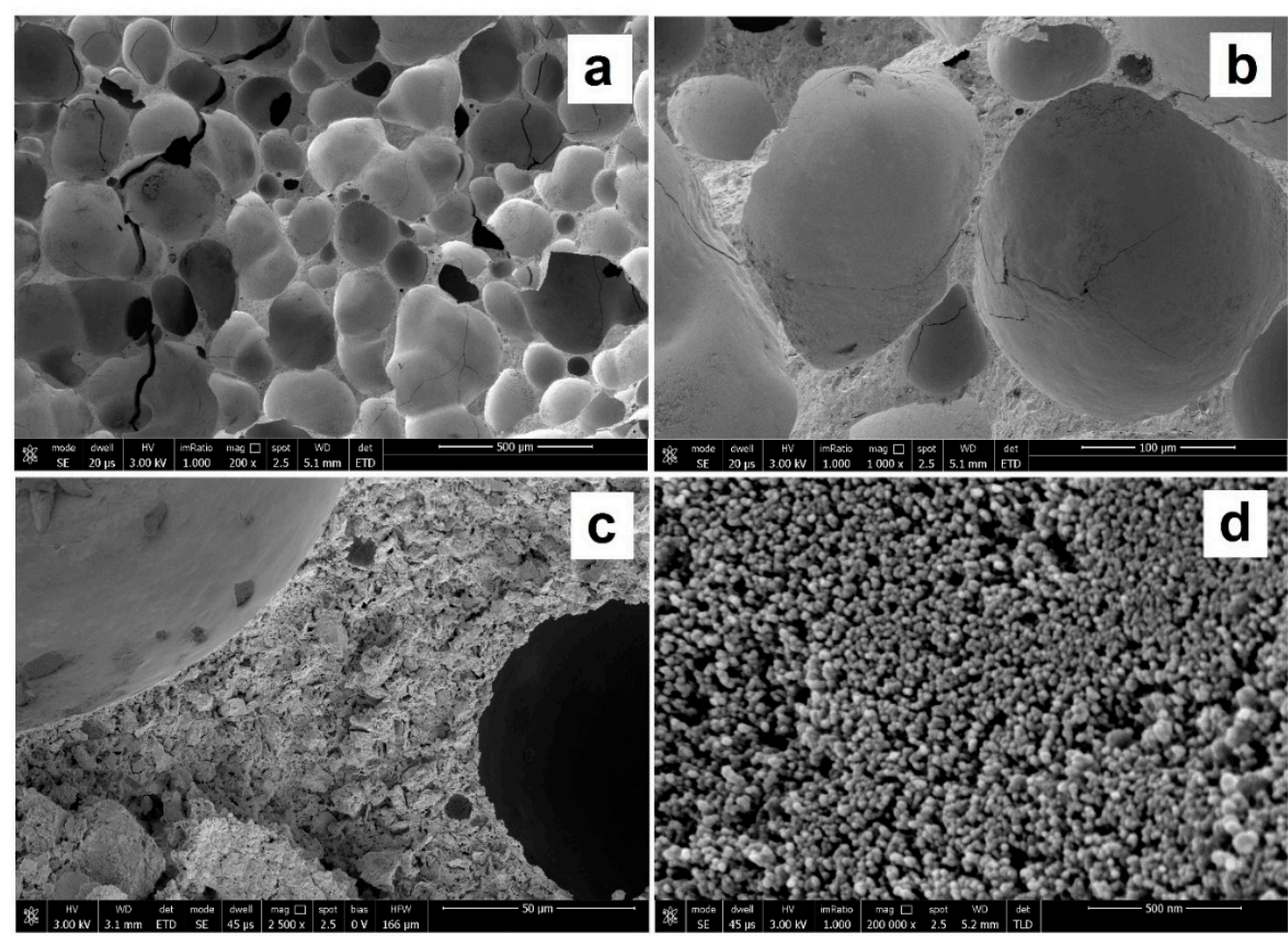

Figure 3. SEM micrographs at 200 (a), 1000 (b), 2500 (c), and 200,000 (d) magnifications of freshly obtained fractured surfaces of GSil03 foams after washing pretreatment (see Section 3.2).

Figure 4 shows the SEM micrographs of the GSil03 sample already examined in Figure 3, but taken before the washing treatment of the sample. These images revealed that the presence of deposits on the surface of the "as-prepared" sample is likely due to salts and microcrystals, which were effectively removed through the washing treatment carried out before the adsorption tests (Figure 3). As will be discussed in Section 3.2, besides freeing the surface from these residues, the washing pretreatment we performed before the adsorption tests removed ions and salts deriving from raw materials and from the geopolymerization reaction, thus making the foamed samples usable as adsorbent materials. 


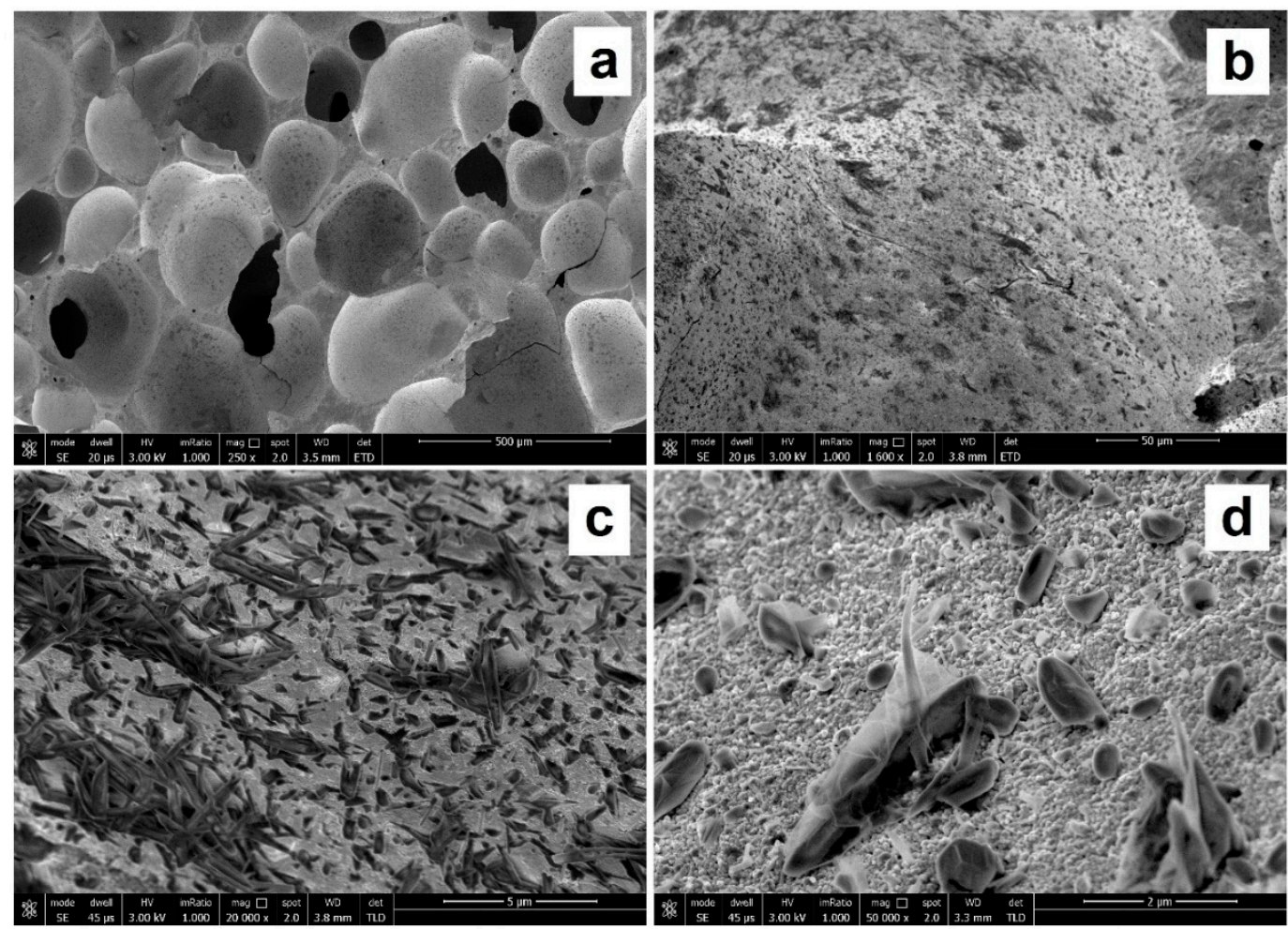

Figure 4. SEM micrographs at 250 (a), 1600 (b), 20,000 (c), and 50,000 (d) magnifications of freshly obtained fractured surfaces of GSil03 foam before washing pretreatment (see Section 3.2).

\subsection{Chemical Composition of Washing Solutions}

The concentration of fluoride, chloride, nitrate, phosphate, sulfate, sodium, and potassium ions in the washing solutions as obtained after each washing cycle are reported in Figure 5. Other common ions, such as acetate, formiate, oxalate, bromide, nitrite, calcium, magnesium, and ammonium, were not detected.

As expected, in the first washing solution, the most abundant ion was sodium, since it was contained in the alkaline activating solution used in the polycondensation reaction. In particular, the concentration of $\mathrm{Na}^{+}$in the first washing cycle was up to $160 \mathrm{mg} / \mathrm{L}$ for GSil03 samples and up to $1550 \mathrm{mg} / \mathrm{L}$ for GSil12 samples (Figure 5C). The great difference in these values could be related to the fact that GSil12 samples presented a greater surface area with respect to GSil03 being characterized by a greater porosity, as discussed in the previous paragraph. Moreover, it is worth pointing out that within each set of samples (GSil03A and GSil03B; GSil12A and GSil12B), the high difference in the release of cations (for example, the GSil12B sample released 2.5 times more $\mathrm{Na}^{+}$ions than GSil12A) could be explained considering again that the " $\mathrm{B}$ " samples have a greater surface area of " $\mathrm{A}$ " samples, being thicker (see Table 2). This hypothesis may be supported by the fact that if we normalize the concentrations in washing solutions of the monitored ions by the mass of the used geopolymer foams, the differences previously observed decrease considerably (Table 3). This observation was in line with our expectations, since the chemical composition of the samples was the same, and since they differed only for the porosity.

All the other monitored ions $\left(\mathrm{K}^{+}, \mathrm{F}^{-}, \mathrm{Cl}^{-}, \mathrm{NO}_{3}{ }^{-}, \mathrm{PO}_{4}{ }^{3-}, \mathrm{SO}_{4}{ }^{2-}\right)$ were detected at much lower concentrations (Figure 5). Fluoride ion (not reported in Figure 5) was the less abundant species being practically absent in the washing solutions of all the specimens examined $(0.000 \pm 0.002 \mathrm{mg} / \mathrm{L}$ for the GSil03A sample, $0.018 \pm 0.006 \mathrm{mg} / \mathrm{L}$ for the GSil03B sample, $0.896 \pm 0.022 \mathrm{mg} / \mathrm{L}$ for the GSil12A sample, and $4.624 \pm 0.032 \mathrm{mg} / \mathrm{L}$ for the GSil12B sample).

The concentrations of all species, with the exception of sodium for the GSil3B sample, decreased proceeding with the washing cycle and, after the fourth washing step, the concentration of chloride, 
fluoride, sulfate, nitrate, and phosphate were well below limits imposed by the Italian Standard law for waste water and defined by the Law Decree 152/2006.

In our opinion, this experimental observation is an indirect confirmation of the effectiveness of our conditioning method that is able to remove ions even for massive foamed samples (as GSil12B), as long as the porosity of the specimens is mostly open porosity.

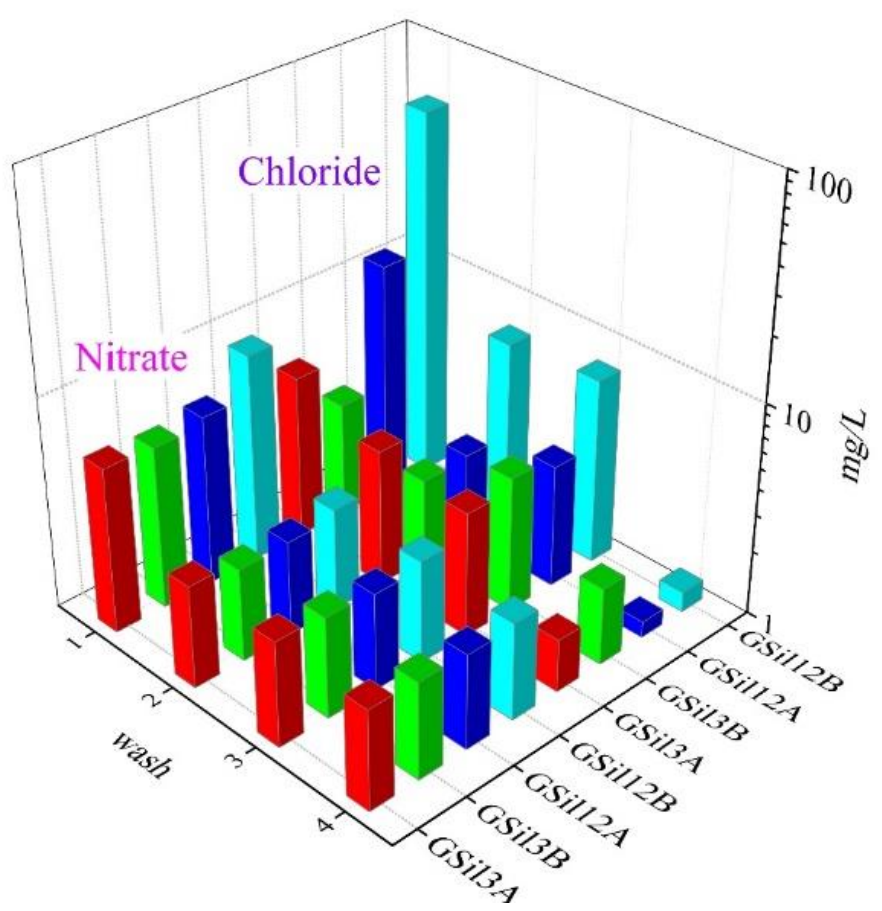

A

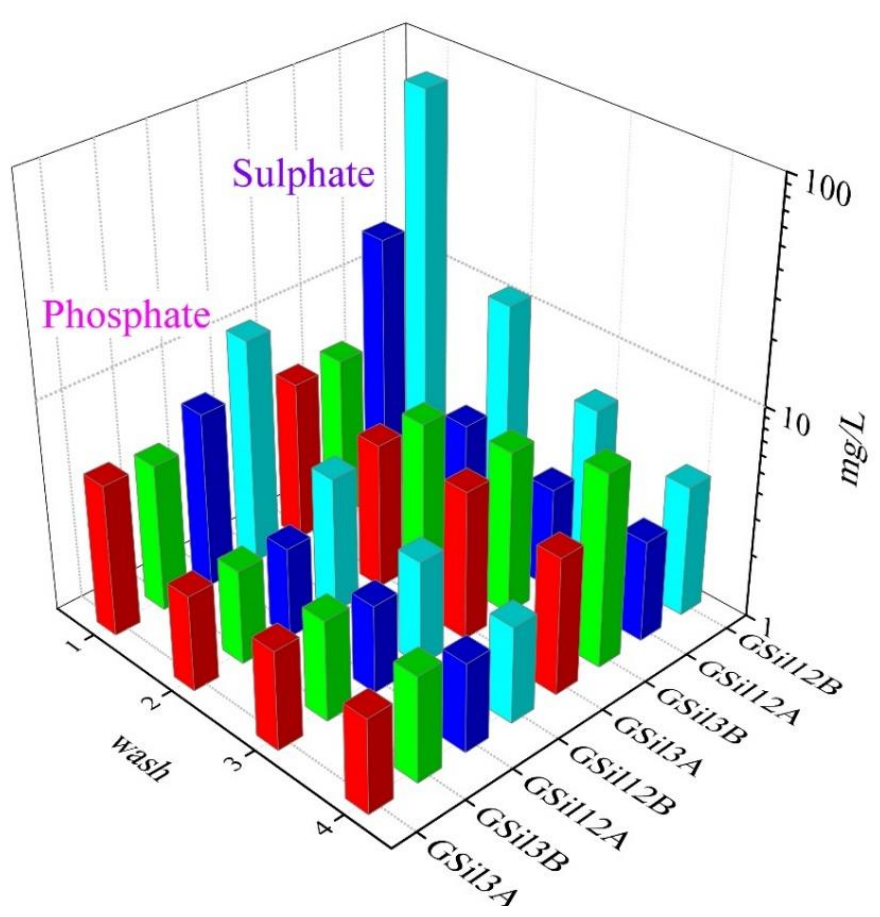

B

Figure 5. Cont. 


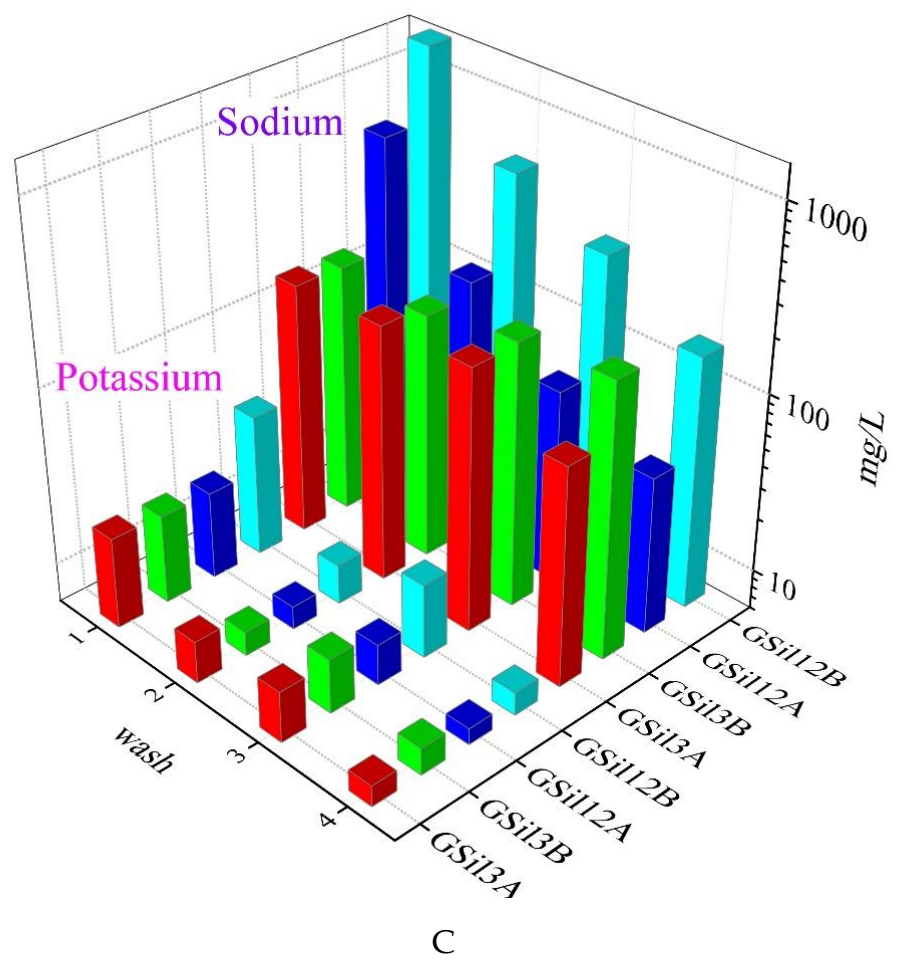

Figure 5. Major ions concentration (nitrate, chloride (A); phosphate, sulfate (B); potassium, sodium (C) expressed as mg/L, collected after each washing step of GSil03 and GSil12 foams.

Table 3. Major ions concentration in washing solutions as determined after each washing cycle of the specimens, expressed as (mg of ion)/(g of hybrid geopolymer foam).

\begin{tabular}{|c|c|c|c|c|c|c|c|}
\hline Sample & $\begin{array}{c}\mathrm{F}^{-} \\
\text {(mg/g of } \\
\text { Adsorbent) }\end{array}$ & $\begin{array}{c}\mathrm{Cl}^{-} \\
\text {(mg/g of } \\
\text { Adsorbent) }\end{array}$ & $\begin{array}{c}\mathrm{NO}_{3}^{-} \\
\text {(mg/g of } \\
\text { Adsorbent) }\end{array}$ & $\begin{array}{c}\mathrm{PO}_{4}{ }^{3-} \\
\text { (mg/g of } \\
\text { Adsorbent) }\end{array}$ & $\begin{array}{c}\mathrm{SO}_{4}{ }^{2-} \\
\text { (mg/g of } \\
\text { Adsorbent) }\end{array}$ & $\begin{array}{c}\mathrm{Na}^{+} \\
\text {(mg/g of } \\
\text { Adsorbent) }\end{array}$ & $\begin{array}{c}\mathrm{K}^{+} \\
\text {(mg/g of } \\
\text { Adsorbent) }\end{array}$ \\
\hline \multicolumn{8}{|c|}{ After wash cycle No. 1} \\
\hline GSil3A & 0.000 & 0.104 & 0.106 & 0.091 & 0.100 & 2.777 & 0.342 \\
\hline GSil3B & 0.000 & 0.019 & 0.033 & 0.028 & 0.033 & 0.860 & 0.106 \\
\hline GSil12A & 0.014 & 0.200 & 0.098 & 0.105 & 0.277 & 9.670 & 0.290 \\
\hline GSil12B & 0.022 & 0.263 & 0.046 & 0.056 & 0.346 & 7.396 & 0.183 \\
\hline \multicolumn{8}{|c|}{ After wash cycle No. 2} \\
\hline GSil3A & 0.000 & 0.076 & 0.053 & 0.049 & 0.084 & 2.895 & 0.178 \\
\hline GSil3B & 0.000 & 0.014 & 0.015 & 0.015 & 0.027 & 0.804 & 0.045 \\
\hline GSil12A & 0.000 & 0.039 & 0.043 & 0.041 & 0.057 & 2.620 & 0.125 \\
\hline GSil12B & 0.006 & 0.033 & 0.015 & 0.021 & 0.053 & 2.464 & 0.048 \\
\hline \multicolumn{8}{|c|}{ After wash cycle No. 3} \\
\hline GSil3A & 0.000 & 0.066 & 0.054 & 0.050 & 0.087 & 3.081 & 0.198 \\
\hline GSil3B & 0.000 & 0.022 & 0.015 & 0.015 & 0.030 & 0.939 & 0.062 \\
\hline GSil12AI & 0.000 & 0.058 & 0.044 & 0.040 & 0.047 & 1.136 & 0.156 \\
\hline GSil12B & 0.000 & 0.035 & 0.014 & 0.014 & 0.026 & 1.432 & 0.072 \\
\hline \multicolumn{8}{|c|}{ After wash cycle No. 4} \\
\hline GSil3A & 0.000 & 0.031 & 0.052 & 0.049 & 0.077 & 1.762 & 0.137 \\
\hline GSil3B & 0.000 & 0.013 & 0.016 & 0.017 & 0.046 & 1.167 & 0.047 \\
\hline GSil12A & 0.000 & 0.017 & 0.000 & 0.038 & 0.043 & 0.662 & 0.106 \\
\hline GSil12B & 0.000 & 0.006 & 0.015 & 0.015 & 0.022 & 0.815 & 0.042 \\
\hline
\end{tabular}


As far as the $\mathrm{pH}$ of washing solutions (Figure 6), it is worth noting that despite the fact that four washing cycles have been able to effectively reduce the major ions concentration, this kind of conditioning treatment was not enough to bring the $\mathrm{pH}$ values within the limits imposed by Italian law (i.e., in the range 5.5-9.5). In particular, after four washing cycles, the $\mathrm{pH}$ decreased below limits just for GSil03A and GSil12A (that is, the thinner samples), while both thicker samples (GSil03B and GSil12B) retained high $\mathrm{pH}$ values, which was neither compliant with the limits imposed by law nor for adsorption tests conditions. For this reason, the samples were subjected to a final wash with a current of ultrapure water until the $\mathrm{pH}$ reached acceptable values (in the range of 7.3-8.6, green diamonds in Figure 6).

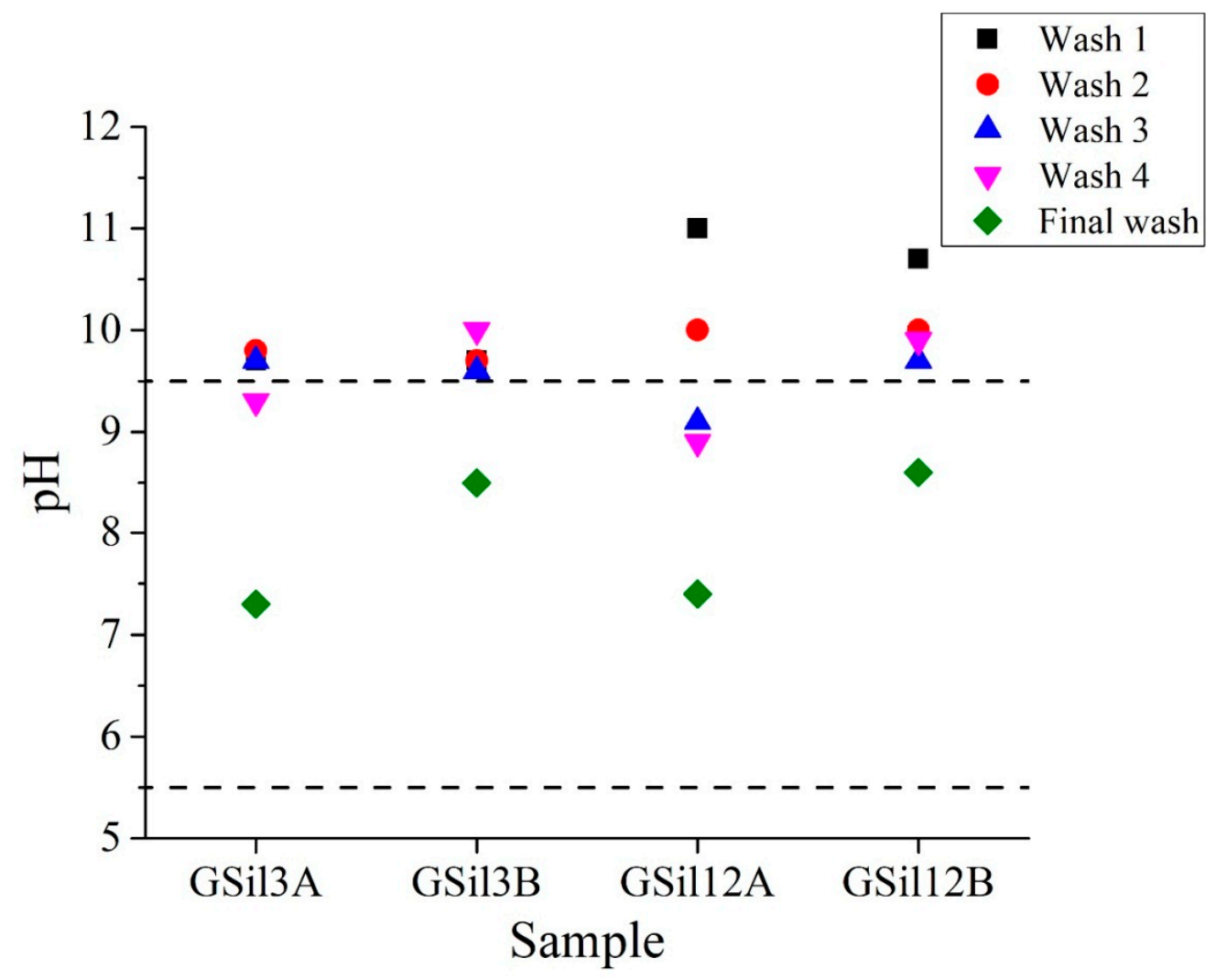

Figure 6. $\mathrm{pH}$ of washing solutions as determined soon after the first (black squares), second (red circles), third (blue triangles), and fourth (magenta triangles) washing cycle and after the final wash with a current of ultrapure water (green diamonds). Dotted lines delimit the $\mathrm{pH}$ range of Italian standard law.

Finally, washing solutions were also analyzed for their content of $\mathrm{Pb}^{2+}, \mathrm{Cd}^{2+}, \mathrm{Cu}^{2+}$, and $\mathrm{Zn}^{2+}$. The detected concentrations of metal cations were always well below limit of detection, thus meaning that overruns of standard limits (fixed by Italian Law Decree 152/2006 and corresponding to $0.002 \mathrm{mg} / \mathrm{L}$, $0.2 \mathrm{mg} / \mathrm{L}, 0.1 \mathrm{mg} / \mathrm{L}$ and $0.5 \mathrm{mg} / \mathrm{L}$ for cadmium, lead, copper and zinc respectively) were not observed. For these reasons, no solution contamination was observed, thus allowing performing adsorption tests.

\subsection{Adsorption and Desorption Tests: Preliminary Results}

After washing treatments, the conditioned foamed samples were dried and then used for absorption tests by dipping them into an aqueous solution with an initial concentration of $20 \mathrm{ppm}$ of each metal cation $\left(\mathrm{Pb}^{2+}, \mathrm{Cd}^{2+}, \mathrm{Cu}^{2+}, \mathrm{Zn}^{2+}\right)$. Figure 7 show an optical photograph of the specimens used for the adsorption tests. It is worth noting that despite the prolonged water treatments that have been performed, no efflorescence has formed on the surface of the samples. 


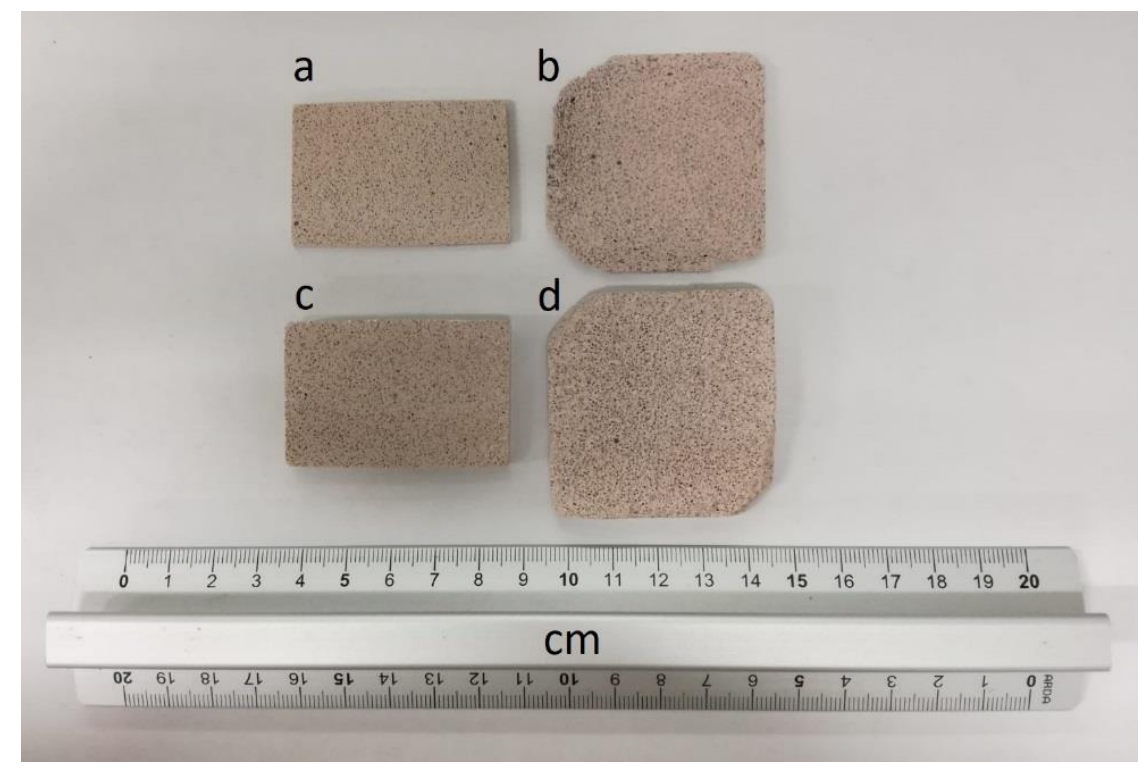

Figure 7. Optical image of GSil03 (a,b) and GSil 12 (c,d) hybrid foams as recovered after the adsorption and desorption tests. The a,c samples are $2 \mathrm{~mm}$ thick, while the b,d samples are $5 \mathrm{~mm}$ thick.

Metal ions concentrations in the solutions after the adsorption test were reported in Table 4. It is apparent that all the tested hybrid foams strongly knock down the metal cations concentration with percentage efficiency values (E) in the range of $99-100 \%$. No significant differences among hybrid foams due to thickness or porosity could be pointed out, neither among the different metal ions tested.

Table 4. Metal cations concentration ( $\mathrm{mg} / \mathrm{L}$ ) after adsorption and desorption tests. The $Q$ values for the adsorption test calculated as $Q=\frac{\left(C_{0}-C_{e}\right) V}{W}$ is also reported (see the Experimental section).

\begin{tabular}{ccccc}
\hline Sample & $\mathbf{Z n}^{2+}$ & $\mathbf{C d}^{2+}$ & $\mathbf{P b}^{2+}$ & $\mathbf{C u}^{2+}$ \\
\hline \multicolumn{5}{c}{ Metal cations concentration after adsorption test $(\mathrm{mg} / \mathrm{L})$} \\
\hline GSil3A & $<$ lod ${ }^{*}$ & $<$ lod & 0.013 & $<$ lod \\
GSil3B & $0.028 \pm 0.009$ & $0.035 \pm 0.008$ & $0.017 \pm 0.004$ & $0.062 \pm 0.008$ \\
GSil12A & $0.007 \pm 0.002$ & $0.008 \pm 0.001$ & $0.015 \pm 0.005$ & $0.015 \pm 0.005$ \\
GSil12B & $0.019 \pm 0.008$ & $0.014 \pm 0.007$ & $0.027 \pm 0.005$ & $0.067 \pm 0.008$ \\
\hline \multicolumn{5}{c}{ Metals concentration after desorption test (mg/L) } \\
\hline GSil3A & $<$ lod & $<$ lod & $<$ lod & $0.014 \pm 0.008$ \\
GSil3B & $<$ lod & $<$ lod & $0.055 \pm 0.004$ & $0.13 \pm 0.01$ \\
GSil12A & $0.114 \pm 0.005$ & $0.016 \pm 0.002$ & $0.209 \pm 0.006$ & $0.31 \pm 0.02$ \\
GSil12B & $<$ lod & $<$ lod & $0.021 \pm 0.002$ & $<$ lod \\
\hline \multicolumn{5}{c}{ Q values for adsorption test $(\mathrm{mg} / \mathrm{g}$ sample) } \\
\hline GSil3A & 0.383 & 0.383 & 0.383 & 0.383 \\
GSil3B & 0.120 & 0.120 & 0.120 & 0.120 \\
GSil12A & 0.341 & 0.341 & 0.341 & 0.341 \\
GSil12B & 0.111 & 0.111 & 0.111 & 0.110 \\
\hline
\end{tabular}

* Limit of detection (lod) for $\mathrm{Zn}^{2+}, \mathrm{Cd}^{2+}, \mathrm{Pb}^{2+}, \mathrm{Cu}^{2+}$ are: $4.2 \mathrm{ng} / \mathrm{L}, 0.8 \mathrm{ng} / \mathrm{L}, 0.5 \mathrm{ng} / \mathrm{L}, 0.5 \mathrm{ng} / \mathrm{L}$ respectively.

With the aim of better quantifying the capability of the foam with respect to metals adsorption, the efficiency for the mass unit of geopolymer foam $(Q)$ was also evaluated. This parameter resulted in a range of $0.1-0.4$ (Table 4). It is important to note that these values refer to a specific test that has been performed using a relatively high adsorbent concentration $(55 \mathrm{~g} / \mathrm{L}, 173 \mathrm{~g} / \mathrm{L}, 63 \mathrm{~g} / \mathrm{L}$, and $191 \mathrm{~g} / \mathrm{L}$ for GSil 3A, GSil 3B, GSil 12A, and GSil 12B, respectively) in a solution with a low metal ions concentration $(20 \mathrm{mg} / \mathrm{L})$, so they do not represent the maximum metal amount that this kind of hybrid geopolymer 
foam could adsorb, but they point out that the studied material is able to effectively remove metal cations from aqueous solutions even if shaped in relatively big monolithic artifacts (see Figure 7) and not as fine powders, as usually done in the literature for geopolymer-based materials [23]. It is interesting to note that $Q$ was highest for GSil3A and GSil12A foams-that is, for samples with smaller thickness-probably because their smaller thickness made it possible for the cations to easily reach even the most internal sites of the specimens.

Finally, since the adsorption capability of metal ions was tested simultaneously, we have also evaluated a cumulative adsorption efficiency, $Q_{t o t}$, according to Equation (2) where $C_{o}$ was the initial total metal concentration (as $\mathrm{mg} / \mathrm{L}$ ), and $C_{e}$ was the final total metal concentration after the adsorption test (as $\mathrm{mg} / \mathrm{L})$. $Q_{\text {tot }}$ was found to be equal to 1.533 for GSil3A, 1.365 for GSil12A, 0.480 for GSil3B, and 0.440 for GSil12B.

Hybrid foams were also tested for their capability of retaining the metal cations absorbed from the solution in the adsorption test described before. In general, the desorption test pointed out that the studied artifacts released very low concentrations of metal ions, in many cases below instrumental detection limits, without significant differences among metals and the different geopolymer samples tested (Table 4).

This indicated that metal ions were somehow linked to the hybrid geopolymer and were efficiently retained.

\subsection{Mechanical Properties}

As pointed out before, differently from what is usually done in the literature where analogous geopolymeric materials are used as fine powders [31], in order to evaluate the possibility of realizing self-standing monolithic filters based on porous geopolymer hybrids, all the adsorption and desorption tests were performed on monoliths. As shown in Figure 7, after the adsorption and desorption tests, all the tested samples were recovered without cracks.

For this reason, aiming at verifying the mechanical properties of the artifact after their immersion in water for a long period of time, compressive strength tests on $50 \times 50 \times 50 \mathrm{~mm}^{3}$ cubic samples were performed according to ASTM D1621 (more details can be found in reference [33]) before and after washing treatments according the same procedure described in Section 2.3.3. In particular, also on these cubic specimens, the washing conditioning was performed until the ion concentration and the $\mathrm{pH}$ of the washing solutions were in agreement with the results obtained for the specimens subjected to the adsorption tests (Section 3.2). Figure 8 shows the stress-strain curves obtained. It is manifest that the mechanical resistance of the cubic specimens tested after their washing was completely comparable with that of the specimens before washing. In particular, for each foam, the stress-strain curves recorded before and after the washing treatment were found to be very similar (Figure 8). Both foams exhibited a well-defined elastic regime, which was noticeable at the early stages of stress. The linear elastic regime remained with an almost constant slope until reaching the yield or unstable collapse point, which was characterized by a sharp load loss for GSil12 and by a less drastic behavior for GSil03. The average values of compressive strength (calculated from the maximum load applied to the specimens and corresponding to the yield or unstable collapse point) and Young's modulus under compression (derived from the slope of the initial linear region of the stress-strain diagram) are reported in Table 5.

To date, to the best of our knowledge, good mechanical properties combined with interesting adsorption capacity have been reported in the literature only if zeolitic tuff is used as a fine aggregate in geopolymeric binders [52,53].

It is worthwhile to point out that the new hybrid material we propose combines good mechanical properties with the capacity to absorb pollutants, as advocated by several authors in the literature, who have recently advanced for other materials based on geopolymers, the possibility to use them also as non-structural construction materials for water tanks, pipes, and damns [54,55]. 


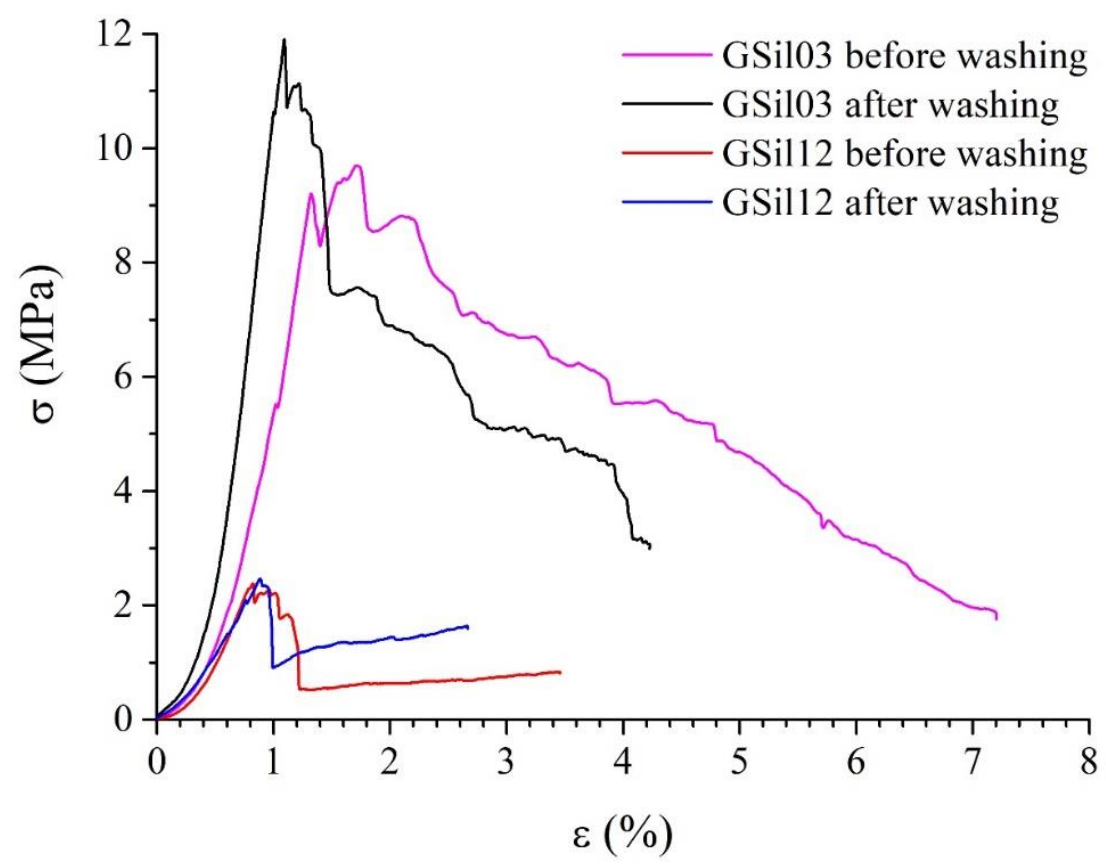

Figure 8. Stress-strain curves in compression of GSil03 and GSil12 samples before and after the washing procedure. See text for details.

Table 5. Compressive strength $\left(\sigma_{\mathrm{c}}\right)$ and Young's modulus (E) of GSil03 and GSil12 as determined before and after washing treatments.

\begin{tabular}{ccccc}
\hline \multirow{2}{*}{ Sample } & \multicolumn{2}{c}{$\sigma_{\mathbf{c}}(\mathbf{M P a})$} & \multicolumn{2}{c}{ E (MPa) } \\
\cline { 2 - 5 } & Before Washing & After Washing & Before Washing & After Washing \\
\hline GSil03 & $10 \pm 1$ & $11 \pm 1$ & $800 \pm 60$ & $1100 \pm 200$ \\
GSil12 & $2.2 \pm 0.6$ & $2.3 \pm 0.8$ & $300 \pm 50$ & $300 \pm 50$ \\
\hline
\end{tabular}

\section{Conclusions}

In this work, hybrid foams realized by the reaction of metakaolin and polysiloxane oligomers have been tested for their efficiency as non-conventional adsorption media for metallic pollutants with the aim of producing self-standing monolithic absorbent substrates. Preliminary results indicated that the studied materials are effective in the adsorption of $\mathrm{Zn}^{2+}, \mathrm{Cd}^{2+}, \mathrm{Pb}^{2+}$, and $\mathrm{Cu}^{2+}$ and they do not release the removed metal ions upon dipping in ultrapure water, even for a very long time. Moreover, we demonstrated that the monolithic artifacts used in this study remain intact and were recovered without cracks after washing treatments and adsorption and desorption tests, thus maintaining good mechanical properties. At variance with the analogous adsorbing materials based on geopolymers described in the literature up to now, which are usually finely ground and reduced to a fine powder, the good mechanical properties of these hybrid materials suggest their application as promising candidates for the production of large, self-standing adsorbent substrates. These substrates could be even easily shaped or directly foamed into precast molds and easily collected when exhausted, which are major advantages over powdered adsorbents.

Author Contributions: Conceptualization, G.R. and E.C.; Data curation, L.R. and V.R.; Formal analysis, E.C., C.F., O.T.; Funding acquisition, R.C. and G.R.; Methodology, E.C., L.R. and V.R.; Resources, R.C.; Supervision, O.T.; Writing—original draft, G.R., E.C. and O.T.; Writing—review \& editing, G.R., O.T., C.F. and R.C.

Funding: This research was funded by Università di Napoli "Parthenope", grant "Support for Individual Research for the 2015-17 Period", Annuity 2017, issued by Rectoral Decree no. 727/2015 and grant "Bando di sostegno alla ricerca competitiva per triennio 2016-2018" D.R. n. 953 issued on 28/11/2016. Authors also thank the grant IDRICA - "Laboratorio Integrato per il monitoraggio, controllo e gestione ottimale Delle Risorse IdriChe e Ambientali"-POR Campania FESR 2014-2020. 
Acknowledgments: Giovanni Morieri e Ms. Luciana Cimino are warmly acknowledged for assistance in laboratory activities. Thanks are also due to ATeN Center, Centro Servizi laboratoristici, Università degli Studi di Palermo, for micro-computed tomography $(\mu \mathrm{CT})$.

Conflicts of Interest: The author declare no conflict of interest.

\section{References}

1. Monaco, D.; Riccio, A.; Chianese, E.; Adamo, P.; Di Rosa, S.; Fagnano, M. Chemical characterization and spatial distribution of PAHs and heavy hydrocarbons in rural sites of Campania Region, South Italy. Environ. Sci. Pollut. Res. 2015, 22, 14993-15003. [CrossRef] [PubMed]

2. Wu, Q.; Leung, J.Y.S.; Geng, X.; Chen, S.; Huang, X.; Li, H.; Huang, Z.; Zhu, L.; Chen, J.; Lu, Y. Heavy metal contamination of soil and water in the vicinity of anabandoned e-waste recycling site: Implications for dissemination ofheavy metals. Sci. Total Environ. 2015, 506, 217-225. [CrossRef] [PubMed]

3. Monaco, D.; Chianese, E.; Riccio, A.; Delgado Sanchez, A.; Lacorte, S. Spatial distribution of Heavy Hydrocarbons, PAHs and Metalsin polluted areas. The case of "Galicia", Spain. Mar. Pollut. Bull. 2017, 121, 1-2. [CrossRef] [PubMed]

4. Kurniawan, T.A.; Chan, G.Y.S.; Lo, W.H.; Babel, S. Physico-chemical treatment techniques for wastewater laden with heavy metals. Chem. Eng. J. 2006, 118, 83-98. [CrossRef]

5. Fu, F.; Wang, Q. Removal of heavy metal ions from wastewaters: A review. J. Environ. Manag. 2011, 92, 407-418. [CrossRef]

6. Hoffmann, F.; Cornelius, M.; Morell, J.; Fröba, M. Silica-Based Mesoporous Organic-Inorganic Hybrid Materials. Angew. Chem. Int. Ed. 2006, 45, 3216-3251. [CrossRef]

7. Wanga, S.; Peng, Y. Natural zeolites as effective adsorbents in water and wastewater treatment. Chem. Eng. J. 2010, 156, 11-24. [CrossRef]

8. Breck, D.W. Zeolite Molecular Sieves: Structure, Chemistry and Use; Wiley: New York, NY, USA, 1974.

9. Liguori, B.; Aprea, P.; Roviello, G.; Ferone, C. Self-supporting zeolites by Geopolymer Gel Conversion. Microporous Mesoporous Mater. 2019, 286, 125-132. [CrossRef]

10. Rees, C.A.; Provis, J.L.; Lukey, G.C.; van Deventer, J.S.J. The mechanism of geopolymer gel formation investigated through seeded nucleation. Colloid Surf. A 2008, 318, 97-105. [CrossRef]

11. Rowles, M.; O'Connor, B. Chemical optimisation of the compressive strength of aluminosilicate geopolymers synthesised by sodium silicate activation of metakaolinite. J. Mater. Chem. 2003, 13, 1161-1165. [CrossRef]

12. Davidovits, J. Geopolymer Chemistry and Applications, 3rd ed.; Institut Geopolymere: Saint Quentin, France, 2011.

13. Habert, G.; Ouellet-Plamondon, C. Recent update on the environmental impact of geopolymers. RILEM Tech. Lett. 2016, 1, 17-23. [CrossRef]

14. Coppola, L.; Bellezze, T.; Belli, A.; Bignozzi, M.C.; Bolzoni, F.; Brenna, A.; Cabrini, M.; Candamano, S.; Cappai, M.; Caputo, D.; et al. Binders alternative to Portland cement and waste management for sustainable construction-Part 1. J. Appl. Biomater. Funct. Mater. 2018, 16, 186-202. [PubMed]

15. Coppola, L.; Bellezze, T.; Belli, A.; Bignozzi, M.C.; Bolzoni, F.; Brenna, A.; Cabrini, M.; Candamano, S.; Cappai, M.; Caputo, D.; et al. Binders alternative to Portland cement and waste management for sustainable construction-Part 2. J. Appl. Biomater. Funct. Mater. 2018, 16, 207-221. [PubMed]

16. Duxson, P.; Provis, J.L.; Lukey, G.C.; Van Deventer, J.S. The role of inorganic polymer technology in the development of 'green concrete'. Cem. Concr. Res. 2007, 37, 1590-1597. [CrossRef]

17. Prud'homme, E.; Michaud, P.; Joussein, E.; Peyratout, C.; Smith, A.; Arrii-Clacens, S.; Clacens, J.M.; Rossignol, S. Silica fume as porogent agent in geo-materials at low temperature. J. Eur. Ceram. Soc. 2010, 30, 1641-1648. [CrossRef]

18. Medri, V.; Papa, E.; Dedecek, J.; Jirglova, H.; Benito, P.; Vaccari, A.; Landi, E. Effect of metallic Si addition on polymerization degree of in situ foamed alkali-aluminosilicates. Ceram. Int. 2013, 39, 7657-7668. [CrossRef]

19. Ducman, V.; Korat, L. Characterization of geopolymer fly-ash based foams obtained with the addition of $\mathrm{Al}$ powder or $\mathrm{H} 2 \mathrm{O} 2$ as foaming agents. Mater. Charact. 2016, 113, 207-213. [CrossRef]

20. Studart, R.; Gonzenbach, U.T.; Tervoort, E.; Gauckler, L.J. Processing routes to macroporous ceramics: A review. J. Am. Ceram. Soc. 2006, 89, 1771-1789. [CrossRef] 
21. van Jaarsveld, J.G.S.; van Deventer, J.S.J.; Lukey, G.C. A comparative study of kaolinite versus metakaolinite in fly ash based geopolymers containing immo- bilized metals. Chem. Eng. Commun. 2004, 191, 531-549. [CrossRef]

22. Bankowski, P.; Zou, L.; Hodges, R. Reduction of metal leaching in brown coal fly ash using geopolymers. J. Hazard. Mater. 2004, 114, 59-67. [CrossRef]

23. Wang, S.; Li, L.; Zhu, Z.H. Solid-state conversion of fly ash to effective adsorbents for Cu removal from wastewater. J. Hazard. Mater. 2007, 139, 254-259. [CrossRef] [PubMed]

24. Yunsheng, Z.; Wei, S.; Qianli, C.; Lin, C. Synthesis and heavy metal immobilization behaviors of slag based geopolymer. J. Hazard. Mater. 2007, 143, 206-213. [CrossRef] [PubMed]

25. Zheng, L.; Wang, W.; Shi, Y. The effects of alkaline dosage and Si/Al ratio on the immobilization of heavy metals in municipal solid waste incineration fly ash-based geopolymer. Chemosphere 2010, 79, 665-671. [CrossRef] [PubMed]

26. Al-Zboon, K.; Al-Harahsheh, M.S.; Hani, F.B. Fly ash-based geopolymer for Pb removal from aqueous solution. J. Hazard. Mater. 2011, 188, 414-421. [CrossRef] [PubMed]

27. Cheng, T.W.; Lee, M.L.; Ko, M.S.; Ueng, T.H.; Yang, S.F. The heavy metal adsorption characteristics on metakaolin-based geopolymer. Appl. Clay Sci. 2012, 96, 90-96. [CrossRef]

28. Ge, Y.; Cui, X.; Li, Y.K.Z.; He, Y.; Zhou, Q. Porous geopolymeric spheres for removal of Cu (II) from aqueous solution: Synthesis and evaluation. J. Hazard. Mater. 2015, 283, 244-245. [CrossRef] [PubMed]

29. Ferone, C.; Capasso, I.; Bonati, A.; Roviello, G.; Montagnaro, F.; Santoro, L.; Turco, R.; Cioffi, R. Sustainable management of water potabilization sludge by means of geopolymers production. J. Clean. Prod. 2019, 229, 1-9. [CrossRef]

30. Pimraksa, K.; Chindaprasirt, P.; Rungchet, A.; Sagoe-Crentsil, K.; Sato, T. Lightweight geopolymer made of highly porous siliceous materials with various $\mathrm{Na} 2 \mathrm{O} / \mathrm{Al} 2 \mathrm{O} 3$ and $\mathrm{SiO} 2 / \mathrm{Al} 2 \mathrm{O} 3$ ratios. Mater. Sci. Eng. A 2011, 528, 6616-6623. [CrossRef]

31. Luukkonen, T.; Sarkkinen, M.; Kemppainen, K.; Rämö, J.; Lassi, U. Metakaolin geopolymer characterization and application for ammonium removal from model solutions and landfill leachate. Appl. Clay Sci. 2016, 119, 266-276. [CrossRef]

32. Ferone, C.; Roviello, G.; Colangelo, F.; Cioffi, R.; Tarallo, O. Novel hybrid organic-geopolymer materials. Appl. Clay Sci. 2013, 73, 42-50. [CrossRef]

33. Roviello, G.; Menna, C.; Tarallo, O.; Ricciotti, L.; Ferone, C.; Colangelo, F.; Asprone, D.; di Maggio, R.; Cappelletto, E.; Prota, A.; et al. Preparation, structure and properties of hybrid materials based on geopolymers and polysiloxanes. Mater. Des. 2015, 87, 82-94. [CrossRef]

34. Roviello, G.; Ricciotti, L.; Ferone, C.; Colangelo, F.; Cioffi, R.; Tarallo, O. Synthesis and Characterization of Novel Epoxy Geopolymer Hybrid Composites. Materials 2013, 6, 3943-3962. [CrossRef] [PubMed]

35. Colangelo, F.; Roviello, G.; Ricciotti, L.; Ferone, C.; Cioffi, R. Preparation and characterization of new geopolymer-epoxy resin hybrid mortars. Materials 2013, 6, 2989-3006. [CrossRef] [PubMed]

36. Roviello, G.; Ricciotti, L.; Ferone, C.; Colangelo, F.; Tarallo, O. Fire resistant melamine based organic-geopolymer hybrid composites. Cem. Concr. Compos. 2015, 59, 89-99. [CrossRef]

37. Strini, A.; Roviello, G.; Ricciotti, L.; Ferone, C.; Messina, F.; Schiavi, L.; Cioffi, R. TiO 2 -Based Photocatalytic Geopolymers for Nitric Oxide Degradation. Materials 2016, 9, 513. [CrossRef] [PubMed]

38. Roviello, G.; Ricciotti, L.; Tarallo, O.; Ferone, C.; Colangelo, F.; Roviello, V.; Cioffi, R. Innovative fly ash geopolymer-epoxy composites: Preparation, microstructure and mechanical properties. Materials 2016, 9, 461. [CrossRef] [PubMed]

39. Roviello, G.; Menna, C.; Tarallo, O.; Ricciotti, L.; Messina, F.; Ferone, C.; Asprone, D.; Cioffi, R. Lightweight geopolymer-based hybrid materials. Compos. Part B Eng. 2017, 128, 225-237. [CrossRef]

40. Colangelo, F.; Roviello, G.; Ricciotti, L.; Ferrándiz-Mas, V.; Messina, F.; Ferone, C.; Tarallo, O.; Cioffi, R.; Cheeseman, C.R. Mechanical and thermal properties of lightweight geopolymer composites containing recycled expanded polystyrene. Cem. Concr. Compos. 2018, 86, 266-272. [CrossRef]

41. Roviello, G.; Ricciotti, L.; Molino, A.J.; Menna, C.; Ferone, C.; Cioffi, R.; Tarallo, O. Hybrid Geopolymers from Fly Ash and Polysiloxanes. Molecules 2019, 24, 3510. [CrossRef]

42. Chowdhury, S.; Mazumder, M.A.J.; Al-Attas, O.; Husain, T. Heavy metals in drinking water: Occurrences, implications, and future needs in developing countries. Sci. Total Environ. 2016, 569, 476-488. [CrossRef]

43. Ja“rup, L. Hazards of heavy metal contamination. Br. Med. Bull. 2003, 68, 167-182. [CrossRef] [PubMed] 
44. Tchounwou, P.B.; Yedjou, C.G.; Patlolla, A.K.; Sutton, D.J. Heavy metal toxicity and the environment. Molecular, Clinical and Environmental Toxicology. Exp. Suppl. 2012, 101, 133-164. [PubMed]

45. Chianese, E.; Tirimberio, G.; Riccio, A. Chemical composition and chemical properties of PM10 and PM2.5 in the urban area of Naples: The effects of air masses origin. J. Atmos. Chem. 2019, 77, 151-169. [CrossRef]

46. Bell, J.L.; Kriven, W.M. Developments in strategic materials. Ceram. Eng. Sci. Proc. 2009, 29, 97-111.

47. Prud'homme, E.; Michaud, P.; Joussein, E.; Peyratout, C.; Smith, A.; Rossignol, S. In situ inorganic foams prepared from various clays at low temperature. Appl. Clay Sci. 2011, 51, 15-22. [CrossRef]

48. Abdollahnejad, Z.; Pacheco-Torgal, F.; Félix, T.; Tahri, W.; Barroso Aguiar, J. Mix design, properties and cost analysis of fly ash-based geopolymer foam. Constr. Build. Mater. 2015, 80, 18-30. [CrossRef]

49. Feng, J.; Zhang, R.; Gong, L.; Li, Y.; Cao, W.; Chenget, X. Development of porous fly ash-based geopolymer with low thermal conductivity. Mater. Des. 2015, 65, 529-533. [CrossRef]

50. Zhang, Z.; Provis, J.L.; Reid, A.; Wang, H. Mechanical, thermal insulation, thermal resistance and acoustic absorption properties of geopolymer foam concrete. Cem. Concr. Compos. 2015, 62, 97-105. [CrossRef]

51. MacKenzie, K.J.D. Innovative applications of inorganic polymers (geopolymers). In Handbook of Alkali-Activated Cements, Mortars and Concretes; Pacheco-Torgal, F., Labrincha, J., Leonelli, C., Palomo, A., Chindaprasit, P., Eds.; Woodhead Publishing: Cambridge, UK, 2014; pp. 777-805.

52. Andrejkovicova', S.; Sudagar, A.; Rocha, J.; Patinha, C.; Hajjaji, W.; Da Silva, E.F.; Velosa, A.; Rocha, F. The effect of natural zeolite on microstructure, mechanical and heavy metals adsorption properties of metakaolin based geopolymers. Appl. Clay Sci. 2016, 126, 141-152. [CrossRef]

53. Huang, Y.; Han, M.; Yi, R. Microstructure and properties of fly ash-based geopolymeric material with 5A zeolite as a filler. Constr. Build. Mater. 2012, 33, 84-89. [CrossRef]

54. Hamaideh, A.; Al-Qarallah, B.; Hamdi, M.R.; Mallouh, S.A.A.; Alshaaer, M. Synthesis of geopolymers using local resources for construction and water purification. J. Water Resour. Prot. 2014, 6, 507-513. [CrossRef]

55. Alshaaer, M.; El-Eswed, B.; Yousef, R.I.; Khalili, F.; Rahier, H. Development of functional geopolymers for water purification, and construction purposes. J. Saudi Chem. Soc. 2012, 20, S85-S92. [CrossRef]

(C) 2019 by the authors. Licensee MDPI, Basel, Switzerland. This article is an open access article distributed under the terms and conditions of the Creative Commons Attribution (CC BY) license (http://creativecommons.org/licenses/by/4.0/). 